\author{
Uma Breve Revisão sobre alguns Aspectos do Álcool \\ Combustível Veicular e a Análise Quantitativa de Espécies \\ Químicas Presentes nesta Matriz Energética \\ Pereira, F. C.;* Lima, F. J. S.; Silva, A. O.
}

Rev. Virtual Quim., 2016, 8 (5), 1702-1720. Data de publicação na Web: 9 de outubro de 2016

http://rvq.sbq.org.br

\title{
A Brief Review about some Aspects of Alcohol Vehicle Fuel and Quantitative Analysis of Chemical Species in this Energy Matrix
}

\begin{abstract}
This review shows several issues and a brief discussion of the Brazilian energy matrix, developed as a source of automotive fuel based on the culture of sugar cane with subsequent process of fermentation for ethanol production. Although ethanol is also present as an additive to gasoline consumed in Brazil, we intend to deal only on the anhydrous ethanol, the genuinely Brazilian fuel. It is scope of this text to present the various chemical constituents present in this energy matrix as well as, listing the main analytical methods used for monitoring and quantification of organic substances, metals and some anions, commonly found in ethanol.
\end{abstract}

Keywords: Ethanol vehicle; clean fuel; heavy metals.

\section{Resumo}

Este texto de revisão apresenta vários aspectos, e uma breve discussão sobre a matriz energética brasileira, desenvolvida como fonte de combustível automotivo baseado na cultura da cana de açúcar, com posterior processo de sua fermentação para a produção de etanol. Embora o álcool etílico também esteja presente, como aditivo da gasolina consumida no território brasileiro, pretende-se discorrer somente sobre o etanol anidro, ou seja, o combustível genuinamente brasileiro. É escopo deste texto apresentar os vários constituintes químicos presentes nesta matriz energética, bem como, elencar as principais metodologias analíticas empregadas para o monitoramento e quantificação de substâncias orgânicas, de metais e de alguns ânions, comumente encontrados no álcool etílico.

Palavras-chave: Etanol veicular; combustível limpo; metais pesados.

* Universidade Federal do Rio Grande do Norte, Instituto de Química, Centro de Ciências Exatas e da Terra, CP 1524, CEP 59072-970, Natal-RN, Brasil.

M claudece@ufrnet.br DOI: $10.21577 / 1984-6835.20160113$ 


\title{
Uma Breve Revisão sobre alguns Aspectos do Álcool Combustível Veicular e a Análise Quantitativa de Espécies Químicas Presentes nesta Matriz Energética
}

\author{
Francisco C. Pereira, * Francisco José S. Lima, Ademir O. da Silva
}

Universidade Federal do Rio Grande do Norte, Instituto de Química, Centro de Ciências Exatas e da Terra, CP 1524, CEP 59072-970, Natal-RN, Brasil.

* claudece@ufrnet.br

Recebido em 9 de setembro de 2016. Aceito para publicação em 5 de outubro de 2016

1. Introdução

2. Alguns Aspectos Qualitativos do Álcool Combustível e Seus Principais Constituintes

3. Aplicações de Técnicas Analíticas Para o Monitoramento de Espécies Químicas em Amostras de Álcool Veicular

4. Determinação de Alguns Compostos Orgânicos em Álcool Combustível

4.1. Aplicação de Técnicas Eletroquímicas

4.2. Aplicação de Técnicas Espectrofotométricas

5. Determinação de Metais em Álcool Combustível

5.1. Aplicação de Técnicas de Absorção Atômica

5.2. Aplicação de Técnicas de Emissão Atômica

5.3. Aplicação de Técnicas Eletroquímicas

5.4. Aplicação de Técnicas Espectrofotométricas

6. Determinação de Alguns Ânions em Álcool Combustível

6.1. Aplicação de Técnicas de Eletroforese Capilar

6.2. Aplicação de Técnicas Condutométricas

6.3. Aplicação de Técnicas Espectrofotométricas

7. Controle do pH do Álcool Combustível

8. Conclusões

\section{Introdução}

O emprego de álcool combustível, como fonte de energia renovável no Brasil, principiou com a criação do Programa Nacional do Álcool (Proálcool) em 1975, através do Decreto 76.593 de 1975 do 
Governo Federal, cujo escopo central vislumbrava desenvolver um programa capaz de responder a eminente demanda energética brasileira, a fim de atenuar as necessidades crescentes de importação de petróleo e minimizar o déficit da balança comercial, altamente desfavorável na década de 70, devido aos constantes aumentos no preço do barril do petróleo no mercado internacional.

O objetivo preliminar deste programa intencionava investigar a viabilidade na adição de teores crescente de álcool à gasolina, como uma fonte alternativa de recurso energético automotor, capaz de agregar outros valores tais como, incorporação de mão de obra local; implementação de um parque industrial sucroalcooleiro; propiciar novas oportunidades para o agronegócio; desenvolvimento socioeconômico de regiões rurais do país; bem como estimular a geração de novas tecnologias nacionais. ${ }^{1}$

Embora o programa tenha apresentado algum revés em meados dos anos oitenta, devido ao corte dos subsídios governamental e a desregulamentação do setor, outros fatores contribuíram para este declínio tais como, os preços competitivos para a exportação do açúcar; a produção, com benefícios fiscais, dos carros populares movidos somente à gasolina e os conflitos internacionais envolvendo alguns países da Organização dos Países Exportadores de Petróleo - OPEP. ${ }^{1}$

Ainda que pese sobre o setor automotivo a responsabilidade pela produção em série dos veículos; durante a etapa inicial do projeto nacional, a Associação Nacional dos Fabricantes de Veículos Automotores (ANFAVEA) assumiu uma posição de mera expectadora, diante das adversidades do Proálcool, motivada pelo fato de que veículo movido a álcool apresenta maior custo de produção, quando comparado com aquele movido somente a gasolina. Diante desta conjuntura, o governo federal sentiu-se compelido a elaborar um pacote de incentivos fiscais, cujo escopo seria a revitalização comercial do produto e a credibilidade do citado programa. ${ }^{1}$

Esta iniciativa foi responsável pela ascensão vertiginosa da produção e comercialização dos veículos chamados dedicados (carros movidos $100 \%$ a álcool). Enquanto a frota nacional, em 1979, resumiase a 4.500 unidades, em 1990 alcançava valores superiores a quatro milhões de veículos automotores. Neste mesmo ano, $76 \%$ de todos os carros leves fabricados no país apresentavam a tecnologia a álcool e suas vendas superavam os $96 \%$ de todos os autoveículos, até então comercializados no país. Estudos estimam que mais da metade da frota metropolitana da cidade de São Paulo é movida a álcool carburante, ou pela sua mistura com gasolina. ${ }^{2-4}$

Contudo, no início deste século, ocorreu uma nova alavancada no programa do Proálcool, quando do lançamento dos carros bicombustível (motores de combustão flexíveis - tecnologia flex), os quais surgiram em 2003, e podem ser alimentados com álcool carburante, gasolina ou pela mistura; independentemente dos teores de cada componente. Em adição, o forte apelo ambientalista, reforça a necessidade na busca de alternativas energéticas capazes de substituir as fontes de recursos fósseis, comprovadas emissoras de poluentes e principais protagonistas das elevadas taxas de dióxido de carbono, cientificamente responsável pelo efeito estufa e pelo aquecimento do planeta.

O processo de consolidação do programa brasileiro do álcool de biomassa foi possível somente graças ao envolvimento de diferentes atores, tanto públicos quanto privados. Dentre aqueles que mais contribuíram para o sucesso deste empreendimento, destacam-se a intervenção direta da Presidente da República, dos Ministérios do Desenvolvimento, Indústria e do Comércio Exterior, das Minas e Energia, da Agricultura, do Planejamento, Petrobras, Agência Nacional do Petróleo, Centro Técnico Aeroespacial, bem como setores interessados na consolidação desta fonte natural como matriz energética. 
$\mathrm{Na}$ condição de atores privados, várias entidades classistas manifestaram seu interesse no sucesso desta empreitada, tais como, a Cooperativa de Produtores de Cana de Açúcar, Açúcar e Álcool do Estado de São Paulo, Sindicato da Indústria da Fabricação do Álcool no Estado de São Paulo, Cooperativa Fluminense dos Produtores de Açúcar e Álcool Ltda., Sindicato da Indústria da Refinação do Açúcar do Município do Rio de Janeiro e a Associação Brasileira da Indústria Química ${ }^{1}$.

Diante da manifestação de interesse dos mais diversificados setores da economia brasileira, em relação ao programa do combustível de biomassa, a síntese de álcool etílico tem apresentado notável crescimento década após década. Enquanto a produção nacional, em 1979, limitava-se a $680.000 \mathrm{~m}^{3}$, correspondendo a $20 \%$ da safra $1979 / 80$, este índice alcançava valores na ordem de $10.600 .000 \mathrm{~m}^{3}$, equivalente a $89 \%$ da safra $1989 / 90$. Somente no biênio 2003/2004 foram vendidos cerca de 14,4 milhões de metros cúbicos de álcool combustível no Brasil. Dados mais recentes indicam que no ano de 2014 o país produziu 28,6 milhões de metros cúbicos, o que representava $30,1 \%$ do etanol mundial. Estas cifras confere ao país, o título de maior produtor de álcool carburante no mundo. No final da década de 90, o álcool veicular já respondia por cerca de $13 \%$ da energia primária consumida no país, sendo responsável pelo abastecimento de 4 milhões de automóveis movidos a etanol; somado a outros seis milhões de veículos alimentados pela mistura álcool e gasolina. Neste mesmo período, o programa já havia contribuído com a geração de cerca de um milhão de novos postos de trabalho. ${ }^{5-10}$

Atualmente, o programa nacional do combustível renovável já rompeu as fronteiras do país alcançando dimensões mundiais. Várias nações do continente americano já manifestaram interesse no projeto Proálcool, tais como, Guatemala, El Salvador, Honduras, Nicarágua, Costa Rica e Panamá. Somente os Estados Unidos, no ano de 2006, produziu 18,5 milhões de metros cúbicos de etanol. No ano de 2011, esta cifra já superava valores de 20 milhões. Outros continentes também já voltaram sua atenção para os favoráveis resultados alcançados através do programa desenvolvido pelo Estado brasileiro. Nações como a Austrália, China, Japão, Índia e a comunidade europeia têm protocolado intenções no seu estudo, a fim de viabilizar sua futura implementação. Dados da literatura estimam que a produção anual de álcool carburante no planeta, já alcança valores superiores a 100 milhões de metros cúbicos. ${ }^{11-13}$

O ritmo de expansão dos processos de degradação ambiental, provocado pelos diferentes meios de produção, cresce vertiginosamente década após década, sem que se vislumbre uma solução para tamanho problema. Por outro lado, cresce também a consciência da sociedade, das instituições civis e dos órgãos ambientalistas, nas busca de sistemas compensatórios que possam apresentar respostas a este tipo de agressão, sejam eles, do ponto de vista de remediação, ou da completa eliminação do agente poluente. Dos resultados obtidos destas iniciativas, dependerá o futuro dos nossos descendentes, uma vez que uma sociedade sustentável é aquela que satisfaz suas necessidades sem diminuir as expectativas das gerações futuras. ${ }^{14}$ Assim, e considerando as propriedades deste combustível, na emissão reduzida de elementos poluentes, é notório prever que sua presença social seja fato consumado.

As discussões, até então apresentadas, comprovam a definitiva consolidação do programa brasileiro de energia renovável; seja através da análise da participação dos distintos segmentos da cadeia produtora/consumidora, seja pela avaliação das políticas públicas de fomento e legislação específica. Em adição, a comunidade internacional, com o apoio de entidades ambientalistas, tem voltado a sua atenção no sentido de conhecer e adotar o projeto pioneiro Proálcool, como fonte de recurso natural, menos poluente, quando comparado com os combustíveis fósseis. 
Diante destes dados é possível depreender que o programa brasileiro do álcool carburante, vislumbrou uma nova vertente energética capaz de se contrapor as fontes convencionais de energia fóssil e não renovável, de vida limitada e altamente poluente. $\mathrm{O}$ projeto despertou o interesse de distintos setores da sociedade civil e vem se consolidando ao longo dos anos, principalmente, devido ao pronto aceite do seguimento consumidor, que percebeu o valor econômico desta empreitada nacional, e a sua contribuição ambiental, capaz de atenuar a emissão de agentes degradantes e comprovadamente nocivos à saúde pública. Assim, o álcool da cana de açúcar empregado como combustível de veículos automotor deverá ser um agente cada vez mais presente na sociedade moderna, com perspectiva de consolidação desta tecnologia em todos os continentes do planeta.

\section{Alguns Aspectos Qualitativos do Álcool Combustível e Seus Principais Constituintes}

O desenvolvimento dos biocombustíveis, especialmente o etanol, além dos aspectos econômicos acima discutidos, também se encontra fortemente vinculado às razões ambientalistas, devido à emissão reduzida de gases responsáveis pelo efeito estufa, e liberação atenuada de substâncias nocivas. Nesta conjuntura, o monitoramento permanente da qualidade do álcool combustível, é uma exigência social cada vez mais crescente, tanto pelo aspecto das substâncias químicas lançadas na atmosfera, após seu processo de combustão; quanto pela sua constituição, durante a oferta deste produto ao mercado consumidor. Assim, o conhecimento prévio da natureza das entidades químicas presentes no etanol carburante, pode assegurar a sua comercialização, com pronto atendimento às normas específicas que regulamentam o setor, respeitando os parâmetros exigidos quanto à qualidade do produto oferecido a sociedade.

Dentro deste contexto, antes da liberação de um lote do produto que se destina ao mercado é absolutamente imperativa que sejam realizadas avaliações químicas preliminares, com o intuito de se estabelecer os teores de cada componente da amostra que se destina a comercialização. Esta investigação deverá levar em conta, todos os aspectos qualitativos e quantitativos dos constituintes químicos; sejam estes de natureza orgânica ou espécies iônicas, tais como metais e alguns ânions. Um estudo prévio deste porte permite que sejam conhecidas, as entidades químicas existentes na matriz, e possibilita depreender, se estes teores presentes serão nocivos à saúde pública ou se apresentam algum risco de dano futuro nos componentes do veículo automotor. Abaixo seguem algumas descrições, e efeitos que as substâncias químicas, comumente presentes no álcool combustível, podem provocar nos automóveis e nos profissionais que manipulam este tipo de produto.

Usualmente, compostos carbonílicos, tais como ésteres, cetonas, aldeídos e uma variedade de ácidos orgânicos, são largamente encontrados no álcool carburante, sendo provenientes dos processos de fermentação alcoólica, e podem, se presentes em elevadas concentrações; comprometer a qualidade do produto. Dentre os mais comuns, acetaldeído e formaldeído, são compostos provavelmente carcinogênicos e ou mutagênicos e precursores da espécie peroxilacetato, potente agente irritante do trato respiratório e de elevada toxicidade. Do ponto de vista dos automóveis, a presença destes aldeídos afeta o processo de ignição dos motores, e elevam os teores de emissão destes poluentes para a atmosfera. Outro aspecto relevante, diz respeito à susceptibilidade destes aldeídos a sua oxidação espontânea, e a sua devida conversão a ácidos carboxílicos. Este processo é responsável pelo aumento da acidez do combustível, comprometendo, desta forma, os componentes metálicos da 
máquina. $^{15}$

Furfural é outro aldeído que, quando presente nesta matriz, pode afetar a produção do álcool etílico, devido a sua atuação como agente inibidor. Além de retardar a síntese do etanol, sua presença pode provocar limitações indesejáveis, devido a sua fácil conversão a álcool furfuril e ácido furóico, alterando a composição química do produto e baixando o $\mathrm{pH}$ do meio. É um composto de elevada toxicidade, capaz de causar danos ao aparelho respiratório, irritante aos olhos, pele e ao trato gastrointestinal. ${ }^{16}$

Em adição, dentre os principais constituintes do etanol combustível, um largo número de metais e ânions inorgânicos podem ser encontrados. Estas espécies salinas são incorporadas nesta matriz, através de diferentes caminhos; seja durante a etapa de cultivo da cana de açúcar, através da absorção da planta pelo solo rico em substâncias inorgânicas; ou através dos processos decorrente da síntese do álcool, ou devido ao seu transporte e ou estocagem. Outra potente fonte de íons metálicos, capaz de alterar as características originais deste combustível, são os tanques de armazenamento, existentes nas refinarias e nos postos de abastecimento, que acabam por contaminar o produto, através de fenômenos de oxidação dos contêineres. ${ }^{17}$

A avaliação preliminar da presença de metais e seus respectivos teores, em combustíveis é de considerável importância no sentido da manutenção da qualidade do produto e da vida útil do automóvel. Algumas destas entidades são responsáveis pelo processo catalítico de várias reações em meio orgânico, e podem contribuir para a degradação e a instabilidade térmica dos combustíveis, bem como, promover a corrosão dos componentes veicular através de reações de oxidação e redução (redox). Em outra mão, a presença de metais, ou espécies organometálicas neste tipo de matriz, pode provocar a sua deposição nos componentes metálicos dos veículos e causar entupimentos nos sistemas de alimentação, lubrificação e escape das máquinas. Quando presentes em altas concentrações, estes constituintes químicos, manifestam um comportamento incompatível com o etanol, e passam a interagir com as partes não metálicas do veículo; tais como, juntas, anéis, conectores, etc., que são constituídos de borrachas, poliuretanos, fibras em geral e demais polímeros sintéticos, empregados para a fabricação de alguns componentes automotivos. Assim, quando os metais, ou compostos organometálicos, passam a se depositar sobre estes artefatos, inicia-se um processo de degradação dos mesmos, seja através de processos oxidativos, seja através de processos catalíticos; o que finda por comprometer a vida útil destes dispositivos, afetando o desempenho do automóvel e provocando vazamento dos líquidos de circulação interna; o que pode aumentar o consumo do motor, bem como, coloca em risco a segurança dos passageiros. As consequências destes eventos, também podem ser bastante pronunciadas, quando se trata de mistura de gasolina e álcool combustível. As propriedades físicas desta miscelânea são profundamente alteradas em muitos aspectos. Dentre os mais importantes, destacam-se a drástica redução da tensão interfacial do sistema e o aumento da pressão de vapor, contribuindo para a volatilização destes líquidos e seu escape através de pequenas fissuras provocadas nas junções danificadas. ${ }^{15,18-20}$

Outra abordagem, de extrema importância que deve ser observada, diz respeito aos níveis de emissão de poluentes, e a sua indissociabilidade na degradação ambiental. Considerando que o uso de etanol carburante tenha atenuado, quantitativamente, os efeitos deletérios destas emissões, quando comparado com os mesmo níveis gerados com a gasolina e similares; a presença dos metais no álcool constitui um agravante; uma vez que estas espécies, não podem ser degradadas e nem destruídas, através da aplicação de qualquer sistema químico ou físico, até então conhecido. Assim, durante o processo de combustão do álcool, estes constituintes são 
lançados na atmosfera, e passam a figurar como agentes impactantes no meio ambiente; podendo depositar-se no solo, na atmosfera e nos corpos d'água, graças à movimentação das massas de ar. Desta forma, os metais pesados, podem se acumular em todos os organismos que constituem a cadeia alimentar do homem, promovendo desordem na saúde individual das pessoas. ${ }^{21-23}$ A seguir são apresentadas algumas relações entre os metais pesados e a saúde pública.

O cádmio é responsável por problemas neoplásticos, teratogênico e pode causar danos ao sistema reprodutivo. O chumbo é prejudicial ao cérebro e ao sistema nervoso em geral, afetando o sangue, rins, sistema digestivo e reprodutor; sendo o responsável pela elevação da pressão arterial, e comprovado agente teratogênico. $O$ mercúrio apresenta efeitos corrosivos violentos na pele e nas membranas da mucosa. Provoca náuseas violentas, vômitos, dor abdominal, diarreia com sangue, danos aos rins e pode levar a morte de um indivíduo, em um período aproximado de 10 dias. Seus sintomas neurológicos são perceptíveis por tremores, vertigens, irritabilidades e depressão, associados à salivação, estomatite e diarreia; descoordenação motora progressiva, perda de visão e audição e deterioração mental, decorrente de uma neuroencefalopatia tóxica, na qual, as células nervosas do cérebro e do córtex cerebelar, estão seletivamente envolvidas. O cromo pode provocar dermatites, úlceras cutâneas, inflamação nasal, câncer de pulmão e perfuração do septo nasal. 0 zinco caracteriza-se por sensações, como paladar adocicado e secura na garganta, tosse, fraqueza, dor generalizada, arrepios, febre, náuseas, vômitos, dentre outros. 0 manganês é responsável por perturbações no sistema respiratório em geral. Além desta propriedade, a síndrome de Parkinson, deficiências no sistema neurológico e falta de coordenação motora, também são atribuídas às altas concentrações de manganês no organismo humano. $\mathrm{O}$ excesso de cobre pode provocar casos de asmas, hipertensão, depressão, esquizofrenia, convulsões, aumento do nível de colesterol e necrose do fígado, como na doença de Wilson. Os altos níveis de cobalto provocam vômitos, náuseas, lesões cardíacas, doenças da tireoide, dores estomacais, cianose periférica, lesões no pâncreas e aumento no volume do coração. $22-25$

\section{Aplicações de Técnicas Analíticas Para o Monitoramento de Espécies Químicas em Amostras de Álcool Veicular}

Considerando as discussões prévias e a importância na manutenção do controle de qualidade do álcool carburante, quanto ao aspecto quantitativo de sua constituição; diferentes técnicas analíticas têm sido empregadas, para o monitoramento dos níveis de concentração das mais diversificadas entidades químicas presentes no etanol combustível. A seguir são reportados alguns resultados analíticos, obtidos de pesquisas cientificas, cujos dados foram extraídos da literatura, que comprovam a importância na avaliação e controle de qualidade desta matriz energética.

Um conciso texto, descrevendo a importância e as potencialidades das técnicas analíticas para o monitoramento das mais diversificadas espécies químicas, tanto de natureza orgânico, quanto inorgânico, nesta matriz veicular é encontrado na literatura. ${ }^{26}$

\section{Determinação de Alguns Compostos Orgânicos em Álcool Combustível}

\subsection{Aplicação de Técnicas Eletroquímicas}

Dentre as substâncias que comumente encontram-se presentes nesta matriz, 
acetaldeído tem sido determinado através de técnicas voltamétricas, empregando eletrodos de mercúrio e carbono vítreo, após as suas interações com o composto 2,4dinitrofenilidrazina. 0 método permitiu sua quantificação em níveis de até $8 \times 10^{-7} \mathrm{~mol} \mathrm{~L}^{-1}$ em amostras de etanol sem a necessidade de tratamento prévio. ${ }^{27}$

Em um procedimento análogo, as substâncias 5-hidroximetilfurfural, 2furfuraldeído, butiraldeído, acetona e metiletilcetona, foram analisadas através de sua capacidade reacional com o composto 2,4dinitrofenilidrazina. ${ }^{17} \mathrm{~A}$ metodologia explora a alta eficiência da técnica de cromatografia liquida, acoplada a sensibilidade da deteç̧ão eletroquímica, para a determinação destas espécies. Os compostos carbonílicos foram determinados em álcool veicular, em valores de concentração na ordem de 5,0 a 6,2 ng $\mathrm{mL}^{-1}$.

Acetaldeído também pode ser analisado através de uma prévia reação de derivatização com hidrazina. ${ }^{28}$ Este protocolo experimental permite a geração de uma espécie eletroativa (hidrazona), passível de seu monitoramento através do emprego de técnicas eletroquímicas, em níveis de concentração tão baixos quanto $2,4 \times 10^{-7} \mathrm{~mol}$ $\mathrm{L}^{-1} \mathrm{em}$ amostras de etanol carburante.

A sensibilidade das técnicas eletroquímicas, acoplada com a eficiência dos métodos cromatográficos, foi testada para a quantificação de acetaldeído em amostras de álcool combustível. ${ }^{29} \quad 0$ protocolo experimental foi desenvolvido a partir da reação do substrato com a substância 2,4dinitrofenilidrazina e, este produto, investigado com eletrodo de carbono vítreo. A utilização do método da adição do analito permitiu a sua recuperação em etanol, em valores de $99 \%$ e limite de detecção de 3,8 $\mu \mathrm{g}$ $\mathrm{L}^{-1}$.

O composto 2-furfuraldeído também pode ser quantificado em amostras de etanol carburante. $^{30} 0$ emprego de técnicas voltamétricas, com eletrodo de carbono vítreo, tem se mostrado hábil para a sua determinação em níveis de concentração entre $9,5 \times 10^{-4}$ a $5,8 \times 10^{-3} \mathrm{~mol} \mathrm{~L}^{-1}$ e limite de detecção de $0,70 \times 10^{-3} \mathrm{~mol} \mathrm{~L}^{-1}$.

Acetato de etila é um contaminante encontrado no álcool combustível veicular, que pode ser produzido através da reação entre o etanol e o ácido acético existente nesta matriz energética. Caetano e colaboradores $^{31}$ descrevem uma metodologia eletroquímica capaz de quantifica-lo em amostras de etanol carburante comercial. A metodologia é baseada no uso de eletrodo de carbono vítreo, revestido com filmes de nafion, dopado com $\mathrm{Fe}^{+3}$. A aplicação prévia de processos derivativos promove a conversão do acetato de etila em ácido acetohidroxâmico. O monitoramento deste produto permitiu a quantificação indireta, do acetato de etila e obteve níveis de detecção de $5,3 \times 10^{-6} \mathrm{~mol} \mathrm{~L}^{-1}$. O método proposto foi validado através do uso de cromatografia gasosa e os resultados apresentaram concordância.

Metanol pode ser considerado como um composto de adulteração do etanol veicular. No Brasil, a legislação vigente, tolera somente $1,0 \% \mathrm{~m} / \mathrm{m}$ de metanol presente no álcool combustível. Romário e colegas $^{32}$ descrevem uma metodologia para a sua direta determinação nesta matriz energética. O procedimento envolve a aplicação de técnicas voltamétricas, em conjunto com tratamento dos dados utilizando calibração multivariada e ferramentas quimiométricas.

Metanol também pode ser quantificado em amostras de álcool veicular através da aplicação da voltametria cíclica, utilizando eletrodo de ouro sem modificação. $O$ ensaio é conduzido em meio alcalino, através do monitoramento do pico de oxidação do composto. $O$ limite de deteç̧ão foi alcançado em $0,045 \%(v / v)$ e a metodologia foi validada através do uso de cromatografia gasosa, empregando $95 \%$ de limite de confiança. ${ }^{33}$

Metodologia analítica de eletroforese capilar também tem encontrado emprego na determinação de aldeídos. Formaldeído, acetaldeído, propionaldeído, acroleína e 
benzaldeído, podem ser monitorados em álcool combustível, através de suas reações com o substrato 2,4-dinitrofenilidrazina ou analisado diretamente. As metodologias permitem suas quantificações em valores de concentração tão baixo quanto 0,41 ppm. ${ }^{34}$

\subsection{Aplicação de Técnicas Espectrofotométricas}

Outro procedimento para a determinação de acetaldeído em etanol automotor é descrito na literatura. $O$ ensaio emprega a técnica de cromatografia liquida de alta eficiência, com detecção espectrofotométrica (UV-Vis). A metodologia utiliza a substância 2,4-dinitrofenilidrazina, como reagente auxiliar, e sua separação isocrática em colunas cromatográficas. A sistemática permite a detecção de acetaldeído em valores de $2 \mu \mathrm{g} \mathrm{L}^{-1}$ em amostras de combustíveis. ${ }^{35}$

Formaldeído, outro contaminante gerado durante o processo de fermentação do etanol, também pode ser quantificado em amostras de combustíveis. Teixeira e colaboradores $^{36}$ têm mostrado a exequibilidade no monitoramento desta espécie, através do emprego de um sistema de injeção em fluxo, com detecção espectrofotométrica. $O$ ensaio pode ser conduzido, a partir da interação do substrato com o composto fluoral, para a formação do 3,5-diacetil-1,4-dihidrolutidina, que pode ser medido em $\lambda 412 \mathrm{~nm}$. O procedimento permite a detecção de até $30 \mu \mathrm{g} \mathrm{L}^{-1}$ com desvio padrão relativo de $2,2 \%$ para amostras em etanol.

$\begin{gathered}\text { Sistemas de análise por injeção } \\ \text { com } \\ \text { sequençãa }\end{gathered}$
espectrofotométrica, também permitem o
estudo quantitativo de aldeídos. Oliveira e
colegas $^{37}$ têm viabilizado um procedimento
operacional, capaz de monitorar aldeídos
alifáticos através de sua reação com a
substância 3 -metil-2-benzotiazolona
hidrazona, na presença de íons $\mathrm{Fe}^{+3}$. A
metodologia foi aplicada em amostras de

combustíveis e apresentou limites de detecção de $60 \mu \mathrm{g} \mathrm{L}^{-1}$ para acetaldeído.

\section{Determinação de Metais em Álcool Combustível}

Considerando que a qualidade do etanol carburante seja assegurada, não somente pelo monitoramento constante dos níveis de contaminantes orgânicos presentes nesta matriz; outros agentes, potencialmente importantes que, via de regra, encontram-se inseridos neste tipo de combustível são os metais. Avaliações prévias das concentrações deste tipo de elemento constituem um estudo de importância singular, uma vez que, suas presenças são associadas a fenômenos corrosivos; notórios atores envolvidos em impactos ambientais, etc. Embora a legislação brasileira seja bastante benevolente no trato desta questão ${ }^{38-40}$ a eficiência dos automóveis e a segurança dos passageiros, podem estar comprometidas com o consumo de um produto que não atenda as especificações necessárias exigidas pela legislação. Os efeitos deletérios dos metais, presentes nesta matriz, foram apresentados nas discussões anteriores.

Assim, diferentes metodologias são descritas na literatura para o monitoramento destas espécies químicas. A seguir são detalhados distintos protocolos experimentais desenvolvidos com a finalidade de quantificar estes constituintes químicos neste tipo de matriz.

\subsection{Aplicação de Técnicas de Absorção Atômica}

O grupo de trabalho do pesquisador Gomes ${ }^{41}$ têm mostrado ser possível analisar os íons metálicos $\mathrm{Cd}^{+2}, \mathrm{Co}^{+2}, \mathrm{Cu}^{+2}, \mathrm{Fe}^{+3}, \mathrm{Ni}^{+2}$, $\mathrm{Pb}^{+2}$ e $\mathrm{Zn}^{+2}$; após aplicação de um procedimento de pré-concentração destes cátions, empregando uma sílica modificada. A validação do sistema, em matrizes de etanol 
combustível, foi realizada através da técnica de absorção atômica e mostrou eficiência ao redor de $100 \%$.

A avaliação do método das adições do padrão foi o sistema empregado por Oliveira e amigos, ${ }^{42}$ para a análise do teor de sódio, existente em amostras de álcool anidro e hidratado, do tipo combustível veicular, através da técnica de absorção atômica. Vinte amostras de etanol foram investigadas através do método quantitativo e, os valores de recuperação, apresentaram índices entre 95 a $104 \%$, comprovando ser possível quantificar sódio em amostras deste combustível através da citada técnica.

A técnica de absorção atômica, em chama, foi empregada para a determinação de ferro em etanol combustível ${ }^{43}$. Amostras de álcool automotivo foram coletadas em postos de abastecimento e mostraram parâmetros quantificatórios na ordem de 0,12 a $1,40 \mathrm{mg} \mathrm{L}^{-1}$ para ferro.

O desenvolvimento de um sistema de préconcentração, empregando uma resina do tipo amberlite funcionalizada, com o ácido 3,4-dihidroxibenzóico; tem permitido a direta quantificação de cobre, ferro, níquel e zinco em combustíveis veicular. A utilização da técnica de absorção atômica, em chama, tem viabilizado as suas detecções em níveis de microteores. ${ }^{44}$

Procedimentos, envolvendo etapas de pré-concentração de analitos, foi a metodologia escolhida por Alcântara e colaboradores $^{45}$, para estudos de teores dos metais $\mathrm{Cu}^{+2}, \mathrm{Ni}^{+2}$ e $\mathrm{Pb}^{+2}$ em amostras de etanol carburante. $\mathrm{O}$ ensaio consiste na utilização de sílica gel, modificada com o composto 2-aminotiazol, responsável pela pré-concentração destas entidades químicas. $O$ estudo quantitativo, através do emprego da técnica de absorção atômica, em chama, permitiu encontrar valores de $\mathrm{Cu}^{+2}(1,18$ $\left.\mathrm{mmol} \mathrm{g}{ }^{-1}\right), \mathrm{Ni}^{+2}\left(1,15 \mathrm{mmol} \mathrm{g}^{-1}\right)$ e $\mathrm{Pb}^{+2}(1,10$ $\mathrm{mmol} \mathrm{g}{ }^{-1}$ ).

O emprego de colunas cromatográficas, modificadas com ácido carboximetilcelulose, tem mostrado grande habilidade para pré- concentrar os íons: $\mathrm{Cd}(\mathrm{II}), \mathrm{Cu}(\mathrm{II}), \mathrm{Cr}(\mathrm{III}), \mathrm{Fe}(\mathrm{III})$, $\mathrm{Ni}(\mathrm{II})$ e Zn(II). Amostras de álcool combustível foram analisadas através da técnica de absorção atômica, em chama, após suas respectivas eluições, e os resultados mostraram que a metodologia permite a remoção de cerca de $100 \%$ destes metais na matriz investigada. ${ }^{46}$

O empacotamento da sílica gel, enriquecida com a substância 2-aminotiazol, tem mostrado ser possível a remoção de cobre, níquel e zinco em amostras de álcool combustível. A aplicação da técnica de absorção atômica mostrou que o processo de adsorção do agente modificador, permite a recuperação de cerca de $100 \%$ destas

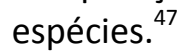

Amostras de etanol carburante podem ser investigadas através da técnica de absorção atômica em forno de grafite. $O$ ensaio permite a determinação das formas iônicas de $\mathrm{Al}, \mathrm{As}, \mathrm{Cu}, \mathrm{Fe}, \mathrm{Mn}$ e Ni. A aplicação, das melhores condições de trabalho, permite a quantificação destas entidades químicas a níveis de picograma. ${ }^{48}$

A determinação de $\mathrm{As}, \mathrm{Cu}, \mathrm{Fe}, \mathrm{Pb}, \mathrm{Sb}$ e $\mathrm{Sn}$, na forma iônica, através do emprego da técnica de absorção atômica, em forno de grafite, foi o procedimento escolhido por Saint'Pierre e colaboradores $^{20}$, para 0 monitoramento destas espécies em etanol automotivo em níveis sub-micromolar.

O grupo de trabalho do pesquisador Silva ${ }^{49}$ descreve um protocolo experimental para a análise de metais, a níveis de traços, através da técnica de absorção atômica em chama. Os íons metálicos cobre, cádmio, cobalto e zinco foram detectados em níveis de concentração de 1,$4 ; 0,2 ; 1,4$; e $1,0\left(\mu \mathrm{g} \mathrm{L}^{-}\right.$ $\left.{ }^{1}\right)$, respectivamente, em amostras de álcool carburante.

As espécies metálicas cobre, ferro, níquel e zinco podem ser determinadas em amostras de etanol carburante, através da metodologia descrita por Oliveira e amigos. ${ }^{50}$ O procedimento utiliza a técnica de absorção atômica em chama. $\mathrm{O}$ emprego das melhores condições experimentais permitiu a 
quantificação destes metais, em baixos níveis de concentração e índices de recuperação variando entre 97 e 102\% para as espécies estudadas.

\subsection{Aplicação de Técnicas de Emissão Atômica}

Diferentes cátions metálicos $\left(\mathrm{Ag}^{+}, \mathrm{Cd}^{+2}\right.$, $\mathrm{Co}^{+2}, \mathrm{Cu}^{+2}, \mathrm{Fe}^{+3}, \mathrm{Mn}^{+2}, \mathrm{Ni}^{+2}$ e $\mathrm{Pb}^{+2}$ ) foram quantificados através do emprego da técnica de geração de plasma indutivamente acoplado. A utilização das melhores condições experimentais permite alcançar limites de detecção em valores traço $(0,08 \mu \mathrm{g}$ $\mathrm{L}^{-1}$ ), em amostras comerciais de etanol. ${ }^{51,52}$

A determinação das espécies $\mathrm{Ag}^{+}, \mathrm{As}^{+3}$, $\mathrm{Cd}^{+2}, \mathrm{Cu}^{+2}, \mathrm{Co}^{+2}, \mathrm{Fe}^{+3}, \mathrm{Mn}^{+2}, \mathrm{Ni}^{+2}, \mathrm{~Pb}^{+2}, \mathrm{Sn}^{+4} \mathrm{e}$ $\mathrm{Tl}^{+}$, em álcool veicular, foi realizada através do emprego da técnica de emissão atômica, com plasma indutivamente acoplado. Através da utilização das melhores condições experimentais, previamente estabelecidas, estes elementos podem ser monitorados a níveis de traços. ${ }^{53}$

\subsection{Aplicação de Técnicas Eletroquímicas}

Técnicas voltamétricas, stripping análise, tem apresentado excelente eficiência no estudo de cobre. $O$ procedimento é baseado no emprego de um eletrodo, a base de parafina modificada com sílica funcionalizada, contendo o composto 2aminotiazol. ${ }^{54}$ Este agente modificador apresenta habilidade, para pré-concentrar cobre em amostras de etanol combustível, e seu ensaio mostrou ser capaz de detectar o íon metálico em níveis de concentração de $3 \times 10^{-8} \mathrm{~mol} \mathrm{~L}^{-1}$.

Em uma avaliação do mesmo porte, os autores também mostram ser possível a análise de níquel em álcool carburante. Um eletrodo compósito, a base de pasta de parafina, modificado com uma sílica funcionalizada, contendo o substrato 2aminotiazol, mostrou-se competente no reconhecimento de níquel nesta amostra comercial, apresentando limite de detecção de $2 \times 10^{-9} \mathrm{~mol} \mathrm{~L}^{-1}$. A aplicação do método das adições do padrão de níquel, neste combustível, mostrou ser possível a sua recuperação em valores entre 96,5 a 102 \%, comprovando ser possível sua análise. ${ }^{55}$

Níquel também pode ser dosado em combustível veicular, através da exploração de suas propriedades redox. $\mathrm{O}$ procedimento descrito emprega um eletrodo de pasta de carbono, modificado com dimetilglioxima, utilizado como agente complexante para esta espécie metálica. ${ }^{56} \mathrm{~A}$ utilização das melhores condições de trabalho permite a sua deteç̧ão em etanol, em valores de concentração entre $1 \times 10^{-8}$ a $7 \times 10^{-8} \mathrm{~mol} \mathrm{~L}^{-1}$.

A voltametria de redissolução anódica foi a técnica empregada por Bergamini e colegas $^{57}$, para a investigação de chumbo em amostra de etanol automotor. A sistematização foi possível, graças a utilização de um eletrodo de pasta de carbono, modificado com uma resina de troca iônica (amberlite IR 120), capaz de incorporar $\mathrm{Pb}^{+2}$. $\mathrm{O}$ procedimento foi aplicado com sucesso, e mostrou ser possível a sua detecção em níveis tão baixo quanto $7,2 \times 10^{-9} \mathrm{~mol} \mathrm{~L}^{-1}$.

A exploração da sensibilidade da técnica voltamétrica de redissolução anódica, tem capacitado o desenvolvimento de uma sistemática, que permite o monitoramento simultâneo de cobre e chumbo, em amostras de etanol combustível. A aplicação das condições ótimas de trabalho, viabilizou a detecção destas entidades em valores tão pequenos, quanto 120 e $235 \mathrm{ng} \mathrm{mL}^{-1}$ para cobre e chumbo, respectivamente. ${ }^{58}$

Eletrodos modificados com filmes de mercúrio, e a utilização de técnicas voltamétricas de redissolução anódica, têm viabilizado a análise de zinco, cobre, chumbo e cádmio em amostras de etanol veicular. ${ }^{59} \mathrm{O}$ emprego das melhores condições de trabalho permitiu suas quantificações no intervalo de concentração entre $1 \times 10^{-9}$ a $1 \times 10^{-8} \mathrm{~mol} \mathrm{~L}^{-1}$.

A presença de zinco em álcool combustível pode ser detectada em valores de concentração de $2,6 \times 10^{-7} \mathrm{~mol} \mathrm{~L}^{-1}$, segundo 
metodologia voltamétrica de redissolução anódica, de acordo com os preceitos descritos por Oliveira e colaboradores. ${ }^{60}$

Ferro pode ser determinado em amostras de etanol veicular através dos procedimentos descritos por Mattos e amigos ${ }^{61}$. Neste trabalho os autores descrevem a construção e aplicação de um eletrodo a base de pasta de carbono, impregnada com o modificador nafion e 1,10 fenantrolina. $O$ sensor apresenta habilidade para o reconhecimento de ferro e a sua detecção em níveis de concentração tão baixo quanto $2,4 \times 10^{-6} \mathrm{~mol}$ $\mathrm{L}^{-1}$.

Íons cobre podem ser monitorados em matrizes de álcool carburante, através do emprego da técnica voltamétrica de redissolução anódica, utilizando um micro eletrodo de ouro. ${ }^{62}$ Aplicando as condições ótimas de análise foi possível construir uma curva de trabalho, apresentando linearidade entre 0,05 a $1,0\left(\times 10^{-6}\right) \mathrm{mol} \mathrm{L}^{-1}$ e limite de detecção de $22 \times 10^{-9} \mathrm{~mol} \mathrm{~L}^{-1}$. Os resultados obtidos, na aplicação da metodologia proposta, em amostras comerciais, foram comparados com ensaios envolvendo a técnica de absorção atômica, em forno de grafite, e os dados apresentaram excelente concordância.

Uma interessante metodologia voltamétrica, para a determinação simultânea de chumbo, cobre e mercúrio em amostras de bioetanol veicular é descrita por Almeida e colegas. ${ }^{63}$ Neste procedimento é utilizado um potenciostato de campo e o emprego de eletrodos de ouro, do tipo screen-printed. $\mathrm{O}$ ajuste do $\mathrm{pH}$ ácido e a aplicação das melhores condições experimentais permitiram alcançar a baixa quantificação de cada um, na ordem de dois ppb e índices de recuperação entre 96 a 104 $\%$ para as espécies estudadas.

Amostras de bioetanol podem ser analisadas, através da aplicação da técnica voltamétrica de acúmulo adsortivo, a fim de quantificar, simultaneamente, íons cobre, chumbo, cádmio, níquel cobalto e zinco, através da metodologia descrita por
Nascimento e colaboradores. ${ }^{64}$ As análises alcançam valores de concentração a níveis de ppb e índices de recuperação de 96\%.

Um eletrodo compósito, à base de grafite e poliuretana, modificado com uma sílica organo funcionalizada, do tipo 2benzotiazoletiol, foi utilizado para a quantificação de íons cobre em amostras de etanol veicular. ${ }^{65} \mathrm{O}$ protocolo utiliza a técnica voltamétrica de redissolução anódica com pulso diferencial. $O$ ensaio permite a quantificação do metal na faixa de concentração entre $1,0 \times 10^{-7}$ a $1,2 \times 10^{-6} \mathrm{~mol} \mathrm{~L}^{-1}$ e limite de detecção de $3,9 \times 10^{-8} \mathrm{~mol} \mathrm{~L}^{-1}$. A metodologia foi validada através da comparação de seus resultados com experimentos envolvendo a técnica de absorção atômica e apresentou concordância.

Um procedimento de análise por injeção em batelada, com detecção voltamétrica, empregando a técnica de redissolução anódica é descrita por Tormin e colaboradores $^{66}$. $O$ ensaio permite a quantificação, simultânea, de cobre, chumbo e cádmio em amostras de bioetanol. Uma curva de trabalho foi obtida, apresentando linearidade no intervalo de concentração entre 12,5 a $200 \mu \mathrm{g} \mathrm{L}^{-1}$ e limite de detecção menor que $1,0 \mu \mathrm{g} \mathrm{L}^{-1}$ além de índices de recuperação entre 87 a $109 \%$ para as espécies analisadas.

Um trabalho de revisão na literatura, sobre as aplicações de metodologias eletroquímicas na determinação de contaminantes inorgânicos em combustíveis automotivos é apresentado por Santos e colegas. ${ }^{67}$ Neste manuscrito é abordada a análise dos principais biocombustíveis veiculares, os quais são o etanol e biodiesel. Para a aplicação deste estudo, nestas duas matrizes energéticas, foram empregadas as técnicas de potenciometria direta, titulação potenciométrica, titulação condutométrica, cromatografia iônica com detecção condutométrica, eletroforese capilar e detecção por condutimetria, voltametria de redissolução anódica de pulso diferencial, de varredura linear e de onda quadrada, 
voltametria de redissolução adsortiva de pulso diferencial, de onda quadrada e de varredura linear, voltametria de redissolução catódica de pulso diferencial, voltametria de pulso diferencial, voltametria de onda quadrada, voltametria cíclica e análise por injeção em fluxo com detecção amperométrica. $\mathrm{O}$ emprego deste leque de técnicas eletroquímicas permitiu a direta quantificação das mais variadas espécies, tais como, $\mathrm{K}^{+}, \mathrm{Cu}^{+2}, \mathrm{~Pb}^{+2}, \mathrm{Zn}^{+2}, \mathrm{Ni}^{+2}, \mathrm{Fe}^{+3}, \mathrm{Sn}^{+4} \mathrm{e}$ alguns ânions, como $\mathrm{Cl}^{-}, \mathrm{SO}_{4}^{-2}, \mathrm{PO}_{4}^{-3}$. Além destas possibilidades, $\mathrm{O}$ artigo de revisão destaca que estas mesmas técnicas eletroquímicas, apresentam potencialidades para o monitoramento de alguns metais, tais como, $\mathrm{V}^{+5}, \mathrm{~Pb}^{+2}, \mathrm{Cd}^{+2}, \mathrm{Cu}^{+2}, \mathrm{Zn}^{+2}, \mathrm{Pt}^{+4}, \mathrm{Hg}^{+2} \mathrm{e}$ outras substâncias orgânicas em amostras de combustíveis fósseis, tais como, gasolina, óleo diesel e querosene, etc.

Eletroforese capilar também pode ser empregada para análise de alguns metais, em etanol automotor com excelente confiabilidade. A metodologia descrita permite a direta quantificação de sódio, potássio, cálcio, magnésio e o cátion amônio, além de alguns ânions inorgânicos. Os limites de detecção foram estimados na faixa de 0,06 a $0,18 \mathrm{mg} \mathrm{L}^{-1}$, após aplicação prévia de processos de volatilização das amostras, seguida de sua resuspensão em meio aquoso. $^{68}$

\subsection{Aplicação de Espectrofotométricas}

Os metais ferro e cobre podem ser estudados, simultaneamente, através de reações de complexação, empregando os reagentes 1,10-fenantrolina, 2,2'-bipiridina e 2,4,6-tri(2-piridil)-1,3,5-triazina. A interação destes metais com estes agentes orgânicos promove a formação de entidades cromóforas, capazes de serem detectadas em valores de concentração de $5 \mu \mathrm{g} \mathrm{L}^{-1}$, e coeficiente de variação de $2,0 \%$, entre as medidas em amostras de etanol carburante, empregando técnicas espectrofotométricas. Estes valores são muito inferiores em relação àqueles estabelecidos pela Resolução $\mathrm{n} N 36$ da Agência Nacional do Petróleo. ${ }^{40,69}$

Medidas espectrofotométricas permitem a análise de cobre em amostras de álcool combustível. $^{70} \mathrm{O}$ procedimento envolve a formação de um complexo, entre o metal e o composto batocuproína, e sua deteç̧ão em níveis de concentração de $6,2 \mu \mathrm{g} \mathrm{L}{ }^{-1}$.

\section{Determinação de Alguns Ânions em Álcool Combustível}

Ainda que a qualidade do etanol combustível esteja, intrinsecamente relacionada com a avaliação constante de seus constituintes e, esta análise seja pragmaticamente, realizada a fim de monitorar, apenas algumas substâncias orgânicas oxigenadas e alguns metais; o estudo dos ânions constitui outra exigência de igual importância que deve ser realizada em todas as amostras comerciais desta matriz veicular.

Considerando que algumas espécies, desta classe de entidades químicas, podem formar sais escassamente solúveis (em água) na presença de certos metais, tais como $\mathrm{PbCl}_{2}, \mathrm{CaSO}_{4}, \mathrm{CuCl}, \mathrm{Hg}_{2} \mathrm{Cl}_{2}, \mathrm{PbSO}_{4}$, dentre outros e, considerando ainda, a baixíssima solubilidade de quase a totalidade dos sais inorgânicos em meio alcoólico; é de extrema importância a devida identificação e quantificação, destes constituintes químicos em álcool automotivo; uma vez que a geração de material insolúvel pode ocasionar o entupimento do sistema de fluxo do combustível e alterar o funcionamento da máquina. Outro aspecto relevante, diz respeito ao emprego do ácido sulfúrico, usado para ajuste do $\mathrm{pH}$ durante a fermentação do etanol, a fim de prevenir a evolução de microrganismo. $O$ excesso deste ácido pode promover a sedimentação de certos metais responsáveis por processos catalíticos importantes. 
De acordo com dados extraídos da literatura, a investigação qualitativa, e a determinação de teores de ânions inorgânicos, em matrizes energéticas automotivas, são matérias que apresentam bastante escassez. Pouquíssimas metodologias são descritas para o acompanhamento destas entidades. Segundo a Resolução da Agência Nacional do Petróleo (ANP) no 36 de 6/12/2005, somente $\mathrm{Cl}^{-}$e SO${ }_{4}^{-}$ ${ }^{2}$ são quantificados através de metodologias potenciométricas \{Norma Brasileira (NBR 10895) da Associação Brasileira de Normas Técnicas (ABNT) \} e volumétricas (NBR 12120), para cloreto e sulfato, respectivamente ${ }^{40}$. Desta forma, a seguir são relatadas as experiências descritas na literatura para a devida quantificação destes substratos em álcool veicular.

\subsection{Aplicação de Técnicas de Eletroforese Capilar}

O grupo de pesquisa de Munoz e colegas ${ }^{68}$ tem mostrado ser possível, a determinação de sulfato, cloreto e nitrato em amostras de álcool automotivo, através da aplicação de eletroforese capilar. O método permite a dosagem destas espécies em valores de concentração na faixa de 0,06 a $0,18 \mathrm{mg} \mathrm{L}^{-1}$.

\subsection{Aplicação de Técnicas Condutométricas}

O emprego de técnicas condutométrica e potenciométrica, para a determinação de cloreto em amostras de etanol veicular é descrito por Avelar e Barbeira ${ }^{71}$. A sistemática permite análise de $\mathrm{Cl}^{-}$em valor médio de concentração de $0,88 \mathrm{mg} \mathrm{L}^{-1}$ com índice de confiabilidade de 95\%.

\subsection{Aplicação de Técnicas Espectrofotométricas}

Metodologia espectrofotometria para a análise de sulfato é descrita por Oliveira e Korn. ${ }^{72} \mathrm{O}$ ensaio pode ser conduzido, com o emprego do composto dimetilsulfonazo de bário, e seu monitoramento através da supressão do sinal de absorbância em $\lambda 665$ $\mathrm{nm}$, devido a formação do $\mathrm{BaSO}_{4}$ insolúvel. $\mathrm{A}$ metodologia, acoplada a um sistema de análise em injeção em fluxo, capacita a determinação de sulfato em valores de concentração de até $10,0 \mathrm{mg} \mathrm{L}^{-1}$ e limite de detecção de $0,27 \mathrm{mg} \mathrm{L}^{-1} \mathrm{em}$ amostras de combustível.

\section{Controle do pH do Álcool} Combustível

Outro dado de alta relevância, a ser considerado em amostras de álcool veicular, é a quantificação do potencial hidrogeniônico do meio $(\mathrm{pH})$. Este parâmetro encontra-se associado aos eventos corrosivos das partes metálicas do automóvel, nos tanques de armazenamento e transporte, bem como nos reservatórios existentes nos postos de abastecimento.

Considerando que, durante os processos de fermentação alcoólica, é necessário o emprego de ácidos minerais, a fim de prevenir a evolução de microrganismos; não obstante, outro fenômeno que contribui para o aumento da acidez deste tipo de matriz, é a oxidação espontânea do etanol, ao seu correspondente ácido orgânico (ácido acético). Assim, a avaliação desta grandeza, constitui um parâmetro de crucial importância, para a manutenção das condições ideais para a comercialização do etanol combustível. Abaixo são elencadas algumas características, relacionadas com o fenômeno de corrosão de peças metálicas automotoras.

O uso de ligas de alumínio na 
indústria automotiva tem crescido nos últimos anos, devido ao melhoramento na eficiência dos automóveis, e o ganho na atenuação dos processos vibratórios do veículo. Assim, alguns componentes veiculares, tais como os pistões, válvulas, bombas, etc., apresentam, em sua constituição, ligas formadas por alumínio. Considerando que os efeitos corrosivos do etanol carburante pode modificar o mecanismo de funcionamento deste dispositivo, com alteração no desempenho do automóvel, o controle adequado das condições ácidas do combustível constitui uma necessidade constante. ${ }^{73}$

Embora os fenômenos galvânicos sejam fatores, constantemente observados em uma interface metal/liquido; a exposição de ligas estruturais, ou responsáveis pela condução dos fluidos de um veículo, à um meio que apresenta alta condutividade elétrica, pode comprometer o bom funcionamento da máquina. Não obstante, a condutividade elétrica do etanol seja relativamente baixa $\left(1,35 \times 10^{-3} \mu \mathrm{S} \mathrm{cm}^{-1}\right)$, este valor pode se elevar abruptamente, para valores próximos a $41 \mu \mathrm{S}$ $\mathrm{cm}^{-1}$ (a uma concentração de $0,1 \mathrm{~mol} \mathrm{~L}^{-1}$ de ácido acético), devido a conversão do álcool etílico a ácido acético. Essa alta condutividade pode destacar a corrosão galvânica e acelerar o ataque químico nos componentes metálicos. ${ }^{74}$

\section{Conclusões}

Considerando a importância do álcool combustível veicular, como fonte de energia renovável e de ser um projeto nacional já consolidado pela sociedade brasileira, é imperativo que a qualidade deste produto seja assegurada pelos órgãos governamentais, a fim de que seja garantido que os consumidores estejam adquirindo uma mercadoria, que atende as especificações estabelecidas nas normas regulamentares.

A fim de confirmar que o etanol carburante comercial é um produto certificado, e se encontra dentro das normativas estabelecidas pelas instituições reguladoras, é necessário que amostras deste produto comercial sejam submetidas a várias análises químicas, tanto de natureza qualitativa, quanto de cunho quantitativo. Para a realização desta tarefa, a química analítica apresenta uma série de metodologias, procedimentos e técnicas que possibilitam a identificação e o monitoramento destas entidades químicas embutidas nesta matriz. A utilização adequada destas ferramentas possibilita que o produto oferecido à sociedade, esteja dentro das relações exigidas pela legislação vigente.

\section{Referências Bibliográficas}

${ }^{1}$ Scandiffio, M. I. G.; Tese de Doutorado, Universidade de Campinas, São Paulo, SP, 2005. [Link]

${ }^{2}$ Associação Nacional dos Fabricantes de Veículos Automotores - ANFAVEA - Anuário Estatístico da Indústria Brasileira Automotiva. Diversos documentos. Disponível em: <http://www.anfavea.com.br/carta.html>. Acesso em: 10 abril 2015.

${ }^{3}$ Moreira, J. R.; Goldemerg, J. The alcohol program. Energy Policy 1999, 27, 229. [CrossRef]

${ }^{4}$ Colon, M.; Pleil, J. D.; Hartlage, T. A.; Guardani, M. L.; Martins, M. H. Survey of volatile organic compounds associated with automotive emissions in the urban airshed of São Paulo, Brazil. Atmospheric Environment 2001, 35, 4017. [CrossRef]

${ }^{5}$ Calle, F. R.; Cortez, L. A. B. Towards proalcool II. A review of the brazilian bioethanol programme. Biomass and Bioenergy 1998, 14, 115. [CrossRef]

${ }^{6}$ Santos, M. H. C. Política e Políticas de uma Energia Alternativa: O Caso do Proálcool, ed. Notrya, Rio de Janeiro, 1993.

${ }^{7}$ União da Agroindústria Canavieira de São Paulo - UNICA, diversos documentos. Disponível 
$<$ http://www.unica.com.br/unicas. Acesso em: 25 de abril 2015.

${ }^{8}$ Wheals, A. E.; Basso, L. C.; Alves, D. M. G.; Amorim, H. V. Fuel ethanol after 25 years. Trends in Biotechnology 1999, 17, 482. [CrossRef]

${ }^{9}$ Pereira, P. A. P.; Santos, L. M. B.; Sousa, E. T.; Andrade, J. B. Alcohol- and gasohol-fuels: A comparative chamber study of photochemical ozone formation. Journal of the Brazilian Chemical Society 2004, 15, 646. [CrossRef]

${ }^{10}$ Pessoa, J. A.; Roberto, I. C.; Menossi, M.; Santos, R. R.; Ortega, S.; Penna, T. C. V. Perspectives on bioenergy and biotechnology in Brazil. Applied Biochemistry and Biotechnology 2005, 121, 59. [CrossRef]

${ }^{11}$ Nogueira, L. A. H. Ethanol from sugarcane for gasohol in Central America: Facts and perspectives. International Sugar Journal 2005, 107, 183. [Link]

${ }^{12}$ Gray, K. A. Cellulosic ethanol - state of the technology. International Sugar Journal 2007, 109, 154. [Link]

${ }^{13}$ Omido, C. R.; Oliveira, S. L.; Shiraishi, R. S.; Magalhães, K. F.; Ferreira, V. S.; Carvalho, A. A.; Kitano, C.; Paula, M. H. Quantification of water in ethanol using a photothermal transparent transducer. Sensors and Actuators B 2013, 178, 581. [CrossRef]

${ }^{14}$ Goldemberg, J. Ethanol for a sustainable energy future. Science 2007, 315, 808. [CrossRef]

${ }^{15}$ Niven, R. K. Ethanol in gasoline: environmental impacts and sustainability review article. Renewable and Sustainable Energy Reviews 2005, 9, 535. [CrossRef]

${ }^{16}$ Prasad, S.; Singh, A.; Joshi, H. C. Ethanol as an alternative fuel from agricultural, industrial and urban residues. Resources, Conservation and Recycling 2007, 50, 1. [CrossRef]

${ }^{17}$ Saczk, A. A.; Okumura, L. L.; Oliveira, M. F.; Zanoni, M. V. B.; Stradiotto, N. R. Determination of aldehydes and ketones in fuel ethanol by high-performance liquid chromatography with electrochemical detection. Chromatographia 2006, 63, 45. [CrossRef]

${ }^{18}$ Silva, I. A.; Campos, R. C.; Curtius, A. J. Determination of lead and copper in kerosene by electrothermal atomic absorption spectrometry: Stabilization of metals in organic media by a threecomponent solution. Journal of Analytical Atomic Spectrometry 1993, 8, 749. [CrossRef]

${ }^{19}$ Filho, N. L. D.; Gushikem, Y.; Polito, W. L.; Moreira, J. C.; Ehirim, E. O. Sorption and preconcentration of metal ions in ethanol solution with a silica gel surface chemically modified with benzimidazole. Talanta 1995, 42, 1625. [CrossRef]

${ }^{20}$ Saint'Pierre, T.; Aucelio, R. Q.; Curtius, A. J. Trace elemental determination in alcohol automotive fuel by electrothermal atomic absorption spectrometry. Microchemical Journal 2003, 75, 59. [CrossRef]

${ }^{21}$ Jenkins, B. M.; Baxter, L. L.; Miles, T. R.; Miles, T. R. J. Combustion properties of biomass. Fuel Processing Technology 1998, 54, 17. [CrossRef]

${ }^{22}$ Baird, C.; Química Ambiental, 2a. ed., Bookman: Porto Alegre, 2002.

${ }^{23}$ Luna, A. S.; Química Analítica Ambiental, Ed. UERJ, Rio de Janeiro, Brasil, 2003.

${ }^{24}$ Delmo, S. V.; Afonso, J. C.; Dutra, P. B.; Para que Servem os Elementos Químicos, Editora Interciência, Rio de Janeiro, 2001.

${ }^{25}$ Jomova, K.; Valko, M. Advances in metalinduced oxidative stress and human disease. Toxicology 2011, 283, 65. [CrossRef]

${ }^{26}$ Oliveira, M. F.; Saczk, A. A.; Okumura, L. L.; Stradiotto, N. R. Analytical methods employed at quality control of fuel ethanol. Energy \& Fuels 2009, 23, 4852. [CrossRef]

${ }^{27}$ Rodgher, V. S.; Okumura, L. L.; Saczk, A. A.; Stradiotto, N. R.; Zanoni, M. V. B. Electroanalysis and determination of acetaldehyde in fuel ethanol using the reaction with 2,4-dinitrophenylhydrazine. Journal of Analytical Chemistry 2006, 61, 889. [CrossRef] 
${ }^{28}$ Rodgher, V. S.; Stradiotto, N. R.; Zanoni, M. V. B.; Barros, A. A. Electroanalysis of acetaldehyde derivatized with hydrazine and determination in fuel ethanol by square wave voltammetry. Química Nova 2006, 29, 662. [Link]

${ }^{29}$ Saczk, A. A.; Okumura, L. L.; Oliveira, M. F.; Zanoni, M. V. B.; Stradiotto, N. R. Determination of acetaldehyde in fuel ethanol by high-performance liquid chromatography with electrochemical detection. Analytical Sciences 2005, 21, 441. [Link]

${ }^{30}$ Saczk, A. A.; Oliveira, M. F.; Okumura, L. L.; Stradiotto, N. R. Voltammetric behavior of 2furfuraldehide reduction in ethanol using glassy carbon electrode. Eclética Química 2002, 27, 141. [CrossRef]

${ }^{31}$ Caetano, L. G.; Takeuchi, R. M.; Santos, A. L.; Oliveira, M. F.; Stradiotto, N. R. Voltammetric determination of ethyl acetate in ethanol fuel using a $\mathrm{Fe}^{3+} / \mathrm{Nafion}^{\circledR}{ }^{-}$-coated glassy carbon electrode. Fuel 2013, 106, 837. [CrossRef]

${ }^{32}$ Romário, E. L.; Abreu, J. E. M.; Paz, A. C.; Silva, M. J. C.; Pontes, S. G. L. Ethanol fuel adulteration with methanol assessed by cyclic voltammetry and multivariate calibration. Fuel 2015, 156, 20. [CrossRef]

${ }^{33}$ Pereira, P. F.; Sousa, R. M. F.; Munoz, R. A. A.; Richter, E. M. Simultaneous determination of ethanol and methanol in fuel ethanol using cyclic Voltammetry. Fuel 2013, 103, 725. [CrossRef]

${ }^{34}$ Pereira, E. A; Tavares, M. F. M.; Cardoso, A. A. Alternative methodologies for the determination of aldehydes by capillary electrophoresis. Journal of Association Official Analytical Chemists International 1999, 82, 1562. [Link]

${ }^{35}$ Saczk, A. A.; Okumura, L. L.; Oliveira, M. F; Zanoni, M. V. B. Stradiotto, N. R.; Rapid and sensitive method for the determination of acetaldehyde in fuel ethanol by highperformance liquid chromatography with UV-Vis detection. Analytical and Bioanalytical Chemistry 2005, 381, 1619. [Link]

${ }^{36}$ Teixeira, L. S. G.; Leão, E. S.; Dantas, A. F.; Pinheiro, H. L. C.; Costa, A. C. S.; Andrade; J. B. Determination of formaldehyde in Brazilian alcohol fuels by flow-injection solid phase spectrophotometry, Talanta 2004, 64, 711. [CrossRef]

${ }^{37}$ Oliveira, F. S.; Leite, B. C. O.; Andrade, M. V. A. S.; Korn, M. Determination of total aldehydes in fuel ethanol by MBTH method sequential injection analysis. Journal of the Brazilian Chemical Society 2005, 16, 87. [CrossRef]

${ }^{38}$ Portaria № 126, de 8.8.2002, Agência Nacional do Petróleo (ANP), Diário Oficial da União 9.8.2002. [Link]

${ }^{39}$ Resolução no 5, de 24.2.2005, Agência Nacional do Petróleo (ANP), Diário Oficial da União 25.2.2005. [Link]

${ }^{40}$ Resolução no 36, de 6.12.2005, Agência Nacional do Petróleo (ANP), Diário Oficial da União 7.12.2005. [Link]

${ }^{41}$ Gomes, L. A. M.; Padilha, P. M.; Moreira, J. C.; Filho, N. L. D.; Gushikem, Y. Determination of metal ions in fuel ethanol after preconcentration on 5-amino-1,3,4thiadiazole-2-thiol modified silica gel. Journal of the Brazilian Chemical Society 1998, 9, 494. [CrossRef]

${ }^{42}$ Oliveira, A. P.; Okumura, L. L.; Neto, J. A. G.; Moraes, M. Evaluation of analyte additions method for sodium determination in fuel ethanol by flame atomic emission spectrometry. Eclética Química 2002, 27, 285. [CrossRef]

${ }^{43}$ Silva, J. E.; Silva, F. A.; Pimentel, M. F.; Honorato, R. S.; Silva, V. L.; Montenegro, B. S. M.; Araujo, N. A. A flow-batch internal standard procedure for iron determination in hydrated ethanol fuel by flame atomic absorption spectrometry. Talanta 2006, 70, 522. [CrossRef]

${ }^{44}$ Teixeira, L. S. G.; Bezerra, M. D.; Lemos, V. A.; Santos, H. C.; Jesus, D. S.; Costa, A. C. S. Determination of copper, iron, nickel, and zinc in ethanol fuel by flame atomic absorption spectrometry using on-line preconcentration system. Separation Science and Technology 2005, 40, 2555. [CrossRef]

${ }^{45}$ Alcântara, I. L.; Roldan, P. S.; Margionte, M. A. L.; Castro, G. R.; Padilha, C. C. F.; Florentino, A. O.; Padilha, P. M. Determination of $\mathrm{Cu}, \mathrm{Ni}$ and $\mathrm{Pb}$ in aqueous medium by FAAS after pre-concentration on 2-aminothiazole modified silica gel. Journal of 
the Brazilian Chemical Society 2004, 15, 366. [CrossRef]

${ }^{46}$ Padilha, P. M.; Padilha, C. C. F.; Rocha, J. C. Flame AAS determination of metal ions in fuel ethanol after preconcentration on acid carboxymethylcellulose (CMCH). Química Analítica 1999, 18, 299. [Link]

${ }^{47}$ Roldan, O. S.; Alcantara, I. L.; Castro, G. R.; Rocha, J. C.; Padilha, C. C. F.; Padilha, P. M. Determination of $\mathrm{Cu}, \mathrm{Ni}$, and $\mathrm{Zn}$ in fuel ethanol by FAAS after enrichment in column packed with 2-aminothiazole-modified silica gel. Analytical and Bioanalytical Chemistry 2003, 375, 574. [CrossRef]

${ }^{48}$ Oliveira, A. P.; Moraes, M.; Neto, J. A. G.; Lima, E. C. Simultaneous determination of Al, As, $\mathrm{Cu}, \mathrm{Fe}, \mathrm{Mn}$, and $\mathrm{Ni}$ in fuel ethanol by GFAAS. Atomic Spectroscopy 2002, 23, 39. [Link]

${ }^{49}$ Silva, E. L.; Budziak, D.; Carasek, E. Determination of trace metals in fuel alcohol by FAAS using $\mathrm{Nb}_{2} \mathrm{O}_{5}-\mathrm{SiO}_{2}$ as sorbent material in a flow injection on-line preconcentration system. Analytical Letters 2004, 37, 1909. [CrossRef]

${ }^{50}$ Oliveira, M. F.; Balbo, V. R.; Andrade, J. F.; Saczk, A. A.; Okumura, L. L.; Stradiotto, N. R. Quantitative assay of copper, iron, nickel, and zinc in fuel ethanol samples by flame atomic absorption spectrometry. Chemistry and Technology of Fuels and Oils 2008, 44, 430. [CrossRef]

${ }^{51}$ Saint'Pierre, T. D.; Frescura, V. L. A.; Curtius, A. J. The development of a method for the determination of trace elements in fuel alcohol by ETV-ICP-MS using isotope dilution calibration. Talanta 2006, 68, 957. [CrossRef]

${ }^{52}$ Saint'Pierre, T. D.; Tormen, L.; Frescura, V. L. A.; Curtius, A. J. The direct analysis of fuel ethanol by ICP-MS using a flow injection system coupled to an ultrasonic nebulizer for sample introduction. Journal of Analytical Atomic Spectrometry 2006, 21, 1340. [CrossRef]

${ }^{53}$ Saint'Pierre, T. D.; Maranhão, T. D.; Frescura, V. L. A.; Curtius, A. J. The development of a method for the determination of trace elements in fuel alcohol by electrothermal vaporization- inductively coupled plasma mass spectrometry using external calibration. Spectrochimica Acta Part B 2005, 60, 605. [CrossRef]

${ }^{54}$ Takeuchi, R. M.; Santos, A. L.; Padilha, P. M.; Stradiotto, N. R. Copper determination in ethanol fuel by differential pulse anodic stripping voltammetry at a solid paraffinbased carbon paste electrode modified with 2-aminothiazole organofunctionalized silica. Talanta 2007, 71, 771. [CrossRef]

${ }^{55}$ Takeuchi, R. M.; Santos, A. L.; Padilha, P. M.; Stradiotto, N. R. A solid paraffin-based carbon paste electrode modified with 2aminothiazole organofunctionalized silica for differential pulse adsorptive stripping analysis of nickel in ethanol fuel. Analytica Chimica Acta 2007, 584, 295. [CrossRef] ${ }^{56}$ Tartarotti, F. O.; Oliveira, M. F.; Balbo, V. R.; Stradiotto, N. R. Determination of nickel in fuel ethanol using a carbon paste modified electrode containing dimethylglyoxime. Microchimica Acta 2006, 155, 397. [CrossRef] ${ }^{57}$ Bergamini, M. F.; Vital, S. I.; Santos, A. L.; Stradiotto, N. R. Lead ions determination in ethanol fuel by differential pulse anodic stripping voltammetry using a carbon paste electrode modified with ion-exchange resin Amberlite IR120. Eclética Química 2006, 31, 45. [CrossRef]

${ }^{58}$ Munoz, R. A. A.; Angnes, L. Simultaneous determination of copper and lead in ethanol fuel by anodic stripping voltammetry. Microchemical Journal 2004, 77, 157. [CrossRef]

${ }^{59}$ Oliveira, M. F.; Saczk, A. A.; Okumura, L. L.; Fernandes, A. P.; Moraes, M.; Stradiotto, N. R. Simultaneous determination of zinc, copper, lead, and cadmium in fuel ethanol by anodic stripping voltammetry using a glassy carbon-mercury-film electrode. Analytical and Bioanalytical Chemistry 2004, 380, 135. [CrossRef]

${ }^{60}$ Oliveira, M. F.; Saczk, A. A.; Okumura, L. L.; Stradiotto, N. R. Determinação de zinco em álcool combustível por voltametria de redissolução anódica. Eclética Química 2002, 27, 153. [CrossRef]

${ }^{61}$ Mattos, C. S.; Carmo, D. R.; Oliveira, M. F.; Stradiotto, N. R. Voltammetric determination 
of total iron in fuel ethanol using a 1,10 fenantroline/nafion carbon paste-modified electrode. International Journal Electrochemical Science 2008, 3, 338. [Link]

${ }^{62}$ Takeuchi, R. M.; Santos, A. L.; Medeiros, M. J.; Stradiotto, N. R. Copper determination in ethanol fuel samples by anodic stripping voltammetry at a gold microelectrode. Microchimica Acta 2009, 164, 101. [CrossRef]

${ }^{63}$ Almeida, E. S.; Richter, E. M.; Munoz, R. A. A. On-site fuel electroanalysis: Determination of lead, copper and mercury in fuel bioethanol by anodic stripping voltammetry using screen-printed gold electrodes. Analytica Chimica Acta 2014, 837, 38. [CrossRef]

${ }^{64}$ Nascimento, D. S.; Insausti, M.; Band, B. S. F.; Lemos, $\mathrm{S}$. G. Simultaneous determination of $\mathrm{Cu}, \mathrm{Pb}, \mathrm{Cd}, \mathrm{Ni}, \mathrm{Co}$ and $\mathrm{Zn}$ in bioethanol fuel by adsorptive stripping voltammetry and multivariate linear regression. Fuel 2014, 137, 172. [CrossRef]

${ }^{65}$ Cesarino, I.; Marino, G.; Cavalheiro, E. T. G. A novel graphite-polyurethane composite electrode modified with thiolorganofunctionalized silica for the determination of copper ions in ethanol fuel. Fuel 2010, 89, 1883. [CrossRef]

${ }^{66}$ Tormin, T. F.; Narciso, L. C. D.; Richter, E. M.; Munoz, R. A. A. Batch-injection stripping voltammetry of metals in fuel bioethanol. Fuel 2014, 117, 952. [CrossRef]

${ }^{67}$ Santos, A. L.; Takeuchi, R. M.; Munoz, R. A. A.; Angnes, L.; Stradiotto, N. R. Electrochemical determination of inorganic contaminants in automotive fuels. Electroanalysis 2012, 24, 1681. [CrossRef]

${ }^{68}$ Munoz, R. A. A.; Richter, E. M.; Jesus, D. P.; Lago, C. L.; Angnes, L. Determination of inorganic ions in ethanol fuel by capillary electrophoresis. Journal of the Brazilian Chemical Society 2004, 15, 523. [CrossRef]

${ }^{69}$ Teixeira, L. S. G.; Brasileiro, J. F.; Borges, M. M.; Cordeiro, P. W. L.; Rocha, S. A. N.; Costa, A. C. S. Determinação espectrofotométrica simultânea de cobre e ferro em álcool etílico combustível com reagentes derivados da ferroína. Química Nova 2006, 29, 741. [Link]

${ }^{70}$ Lu, Q.; Wei, J. F.; Collins, G. E.; Morris, R. E.; Serino, P. M.; Guo, Y. Rapid determination of dissolved copper in jet fuels using bathocuproine. Energy \& Fuels 2003, 17, 699. [CrossRef]

${ }^{71}$ Avelar, H. D.; Barbeira, P. J. S. Conductometric determination of total acidity and chloride content in automotive fuel ethanol. Fuel 2007, 86, 299. [CrossRef]

${ }^{72}$ Oliveira, F. S.; Korn, M. Spectrophotometric determination of sulphate in automotive fuel ethanol by sequential injection analysis using dimethylsulphonazo(III) reaction. Talanta 2006, 68, 992. [CrossRef]

${ }^{73}$ Traldi, S. M.; Costa, I.; Rossi, J. L. Corrosion of spray formed Al-Si-Cu alloys in ethanol automobile fuel. Advanced Powder Technology |/ 2001, 189, 352. [Link]

${ }^{74}$ Jeuland, N.; Montagne X.; Gautrot, X. Potentiality of ethanol as a fuel for dedicated engine. Oil \& Gas Science and Technology Revue d'IFP 2004, 59, 559. [CrossRef] 